\title{
aeropuerto de nueva york nuevo hangar para reactores
}

Informacion amablemente facilitada por The Port of New York Authority

El nuevo hangar del Aeropuerto Internacional de Idlewild, de Nueva York (EE. UU.), proyectado y construí,do bajo la dirección del Port of New York Authority, destinado a los servicios de líneas aéreas extranjeras, está formado por una estructura central metálica, que constituye el cuerpo resistente del hangar.

A uno y otro lado de este cuerpo central, donde se han instalado los servicios, vuelan dos grandes ménsulas que sostienen una serie de cables en la parte superior. La superficie total cubierta es de $120 \times 182 \mathrm{~m}$. Este hangar, una vez terminado, costará del orden de 500 millones de pesetas, incluyendo en esta suma varias obras accesorias, de las cuales la más importante es una pista de rodadura que da acceso al hangar.

Los objetivos del proyecto inicial se dirigieron hacia una concepción moderna, capaz de alojar las grandes aeronaves, tipo Boeing 707, equipadas con tracción a reacción, cuyas dimensiones son de $13 \mathrm{~m}$ de altura, $42 \mathrm{~m}$ de envergadura y $45 \mathrm{~m}$ de longitud total. No se olvidó tampoco en la redacción de dicho proyecto los grandes principios de economía y de lograr una disposición tal que los gastos de conservación se vieran reducidos en una gran medida.

Con objeto de no ser sorprendidos por las actuales mejoras mecánicas y dimensionales de estos grandes reactores, los proyectistas partieron de un compartimiento básico en el que se previeron $13 \mathrm{~m}$ de altura, $51 \mathrm{~m}$ de anchura y $56 \mathrm{~m}$ de la parte anterior a la posterior, incluyendo un hueco, para meter el morro del avión, en el cuerpo central del hangar, que-como se dijo anteriormente-se ha reservado para los servicios del hangar.

Inicialmente el hangar albergará seis naves, tres bajo cada una de las ménsulas, y si se necesitase más espacio para otros aparatos se podría habilitar extendiendo la construcción actual a ambos lados del hangar.

La parte más importante de la estructura es la cubierta. La parte situada bajo las dos grandes ménsulas no lleva soporte alguno, facilitando así la libre maniobra de los aviones que en él entren. El problema capital consistió en hallar una solución adecuada en todos los campos que fueron motivo de consideración en el proyecto. La solución definitiva - como queda apuntado-ha consistido en dos voladizos levantados con una máxima economía. Una ménsula normal volando $48 \mathrm{~m}$ hubiera requerido un canto central de unos $7 \mathrm{~m}$. Este tipo de vigas de gran canto tienen el grave inconveniente de crear un espacio muerto de gran volumen que hay que calentar, drenar e iluminar, con el consiguiente encarecimiento de la conservación.

En la solución final las ménsulas se han suspendido con cables amarrados a las vigas, cuyas cabezas enrasan en los dos faldones de pendiente hacia el interior.

Cada ménsula está constituída por 6 vigas cajón, que se unen al entramado central o cuerpo por medio de rótulas a unos $9,50 \mathrm{~m}$ de altura del suelo.

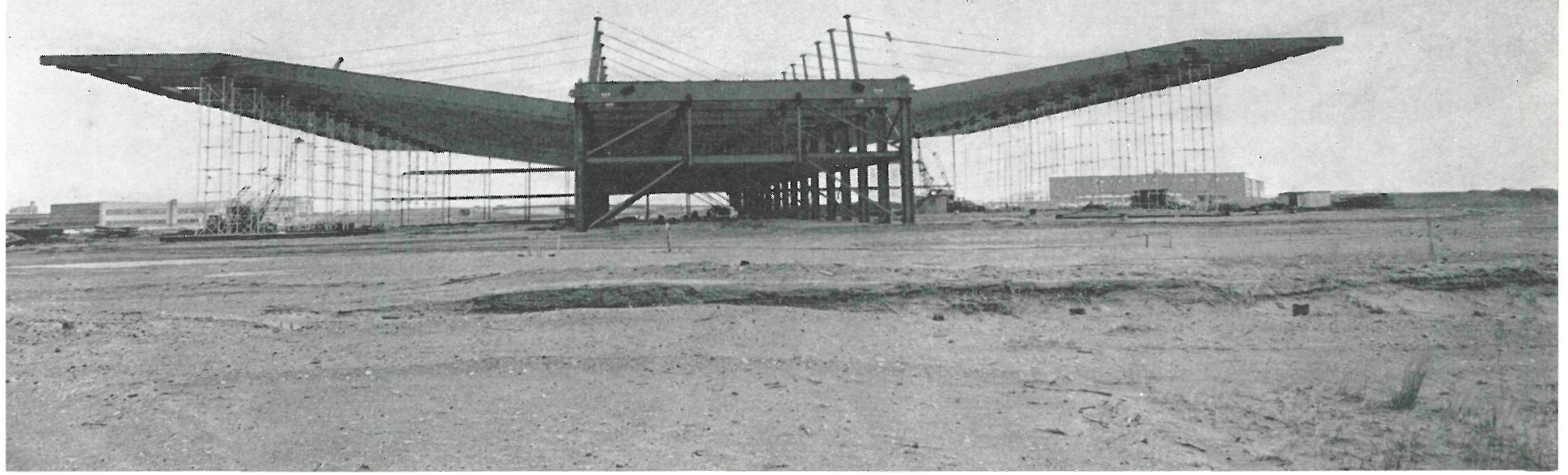


El cuerpo central está realizado a base de un entramado metálico formando dos plantas. Las vigas transversales de este cuerpo, y en la parte superior, son una continuación de las que vuelan formando ménsulas, de 1,50 metros de canto y $0,90 \mathrm{~m}$ de anchura.

El entramado metálico del cuerpo central sirve de soporte de la cubierta, absorbe los esfuerzos de las ménsulas y sirve de anclaje de los cables que suspenden las vigas que vuelan.

Los cables parten de un anclaje en una de las vigas del cuerpo central y se dirigen hacia la viga paralela y opuesta, donde se han levantado unos montantes para apoyo de los cables, y se extienden, ulteriormente, hasta su otro punto de anclaje situado en la viga que vuela y a $33 \mathrm{~m}$ a partir del cuerpo central. La carga prevista para estos cables de suspensión, de $60 \mathrm{~mm}$ de diámetro, es de $5.624 \mathrm{~kg} / \mathrm{cm}^{2}$, y su resistencia a ruptura es de 14.000 kilogramos $/ \mathrm{cm}^{2}$. Con objeto de reducir las dimensiones de los anclajes éstos se han realizado con acero de gran resistencia a la tracción. En los anclajes situados en el cuerpo central los cables se terminan con el abultamiento de esferitas en las extremidades, mientras que en el anclaje de la otra extremidad los cables terminan en una pieza con rosca, la cual se acopla a un tensor para poder tesar después de terminar el montaje de la ménsula o cuando sa haga necesario.

\section{Montaje}

Se empezó montando las columnas o soportes sobre cabezales previamente preparados sobre grupos de pilotes, en número de 25 por soporte, de madera y de 25 toneladas de capacidad cada uno. En la sumisión se admitía la posibilidad de poder emplear pilotes de hormigón, pero el contratista prefirió los de madera. La longitud de estos pilotes varía de 10 a $15 \mathrm{~m}$. Los cabezales colocados sobre estos pilotes son de hormigón de $280 \mathrm{~kg} / \mathrm{cm}^{2}$. En esta parte del proyecto, así como en la otra, el propósito consistía, constructivamente, en reducir los componentes dentro de la medida de lo posible.

Los 32 soportes montados sobre estos pilotes son los que sostienen el armazón de esta simple estructura que forma el cuerpo central y que sirve de apoyo para la cubierta.
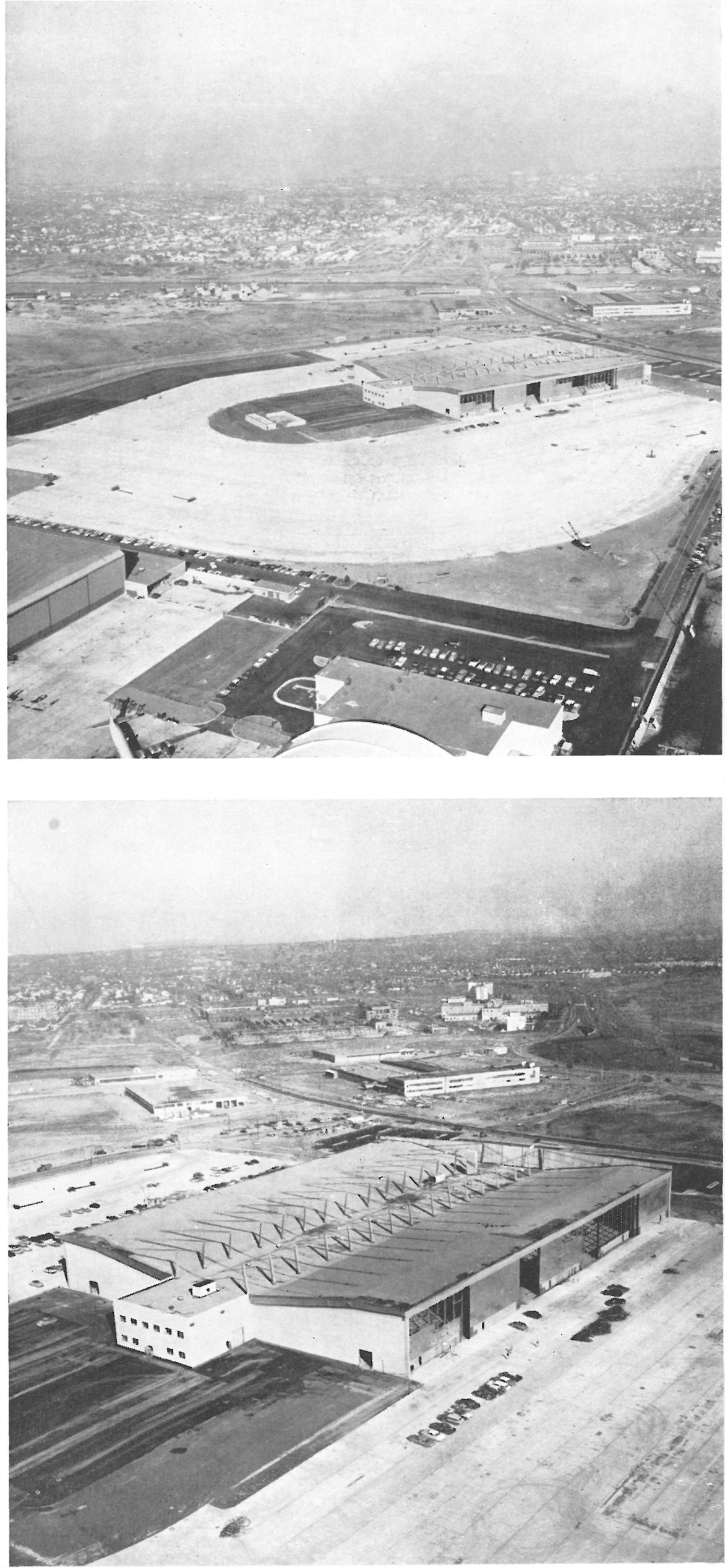


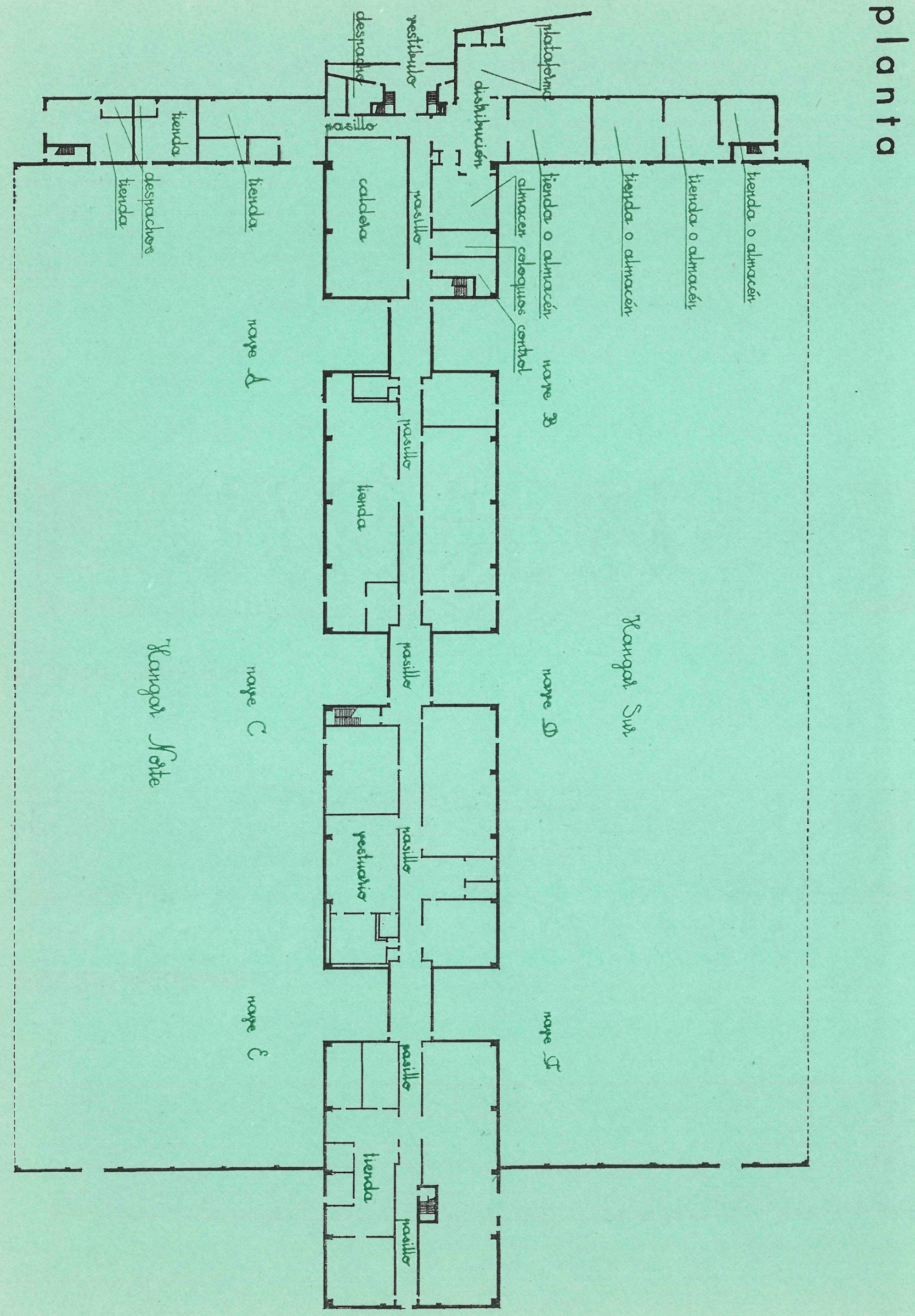




\section{alzado oriental}

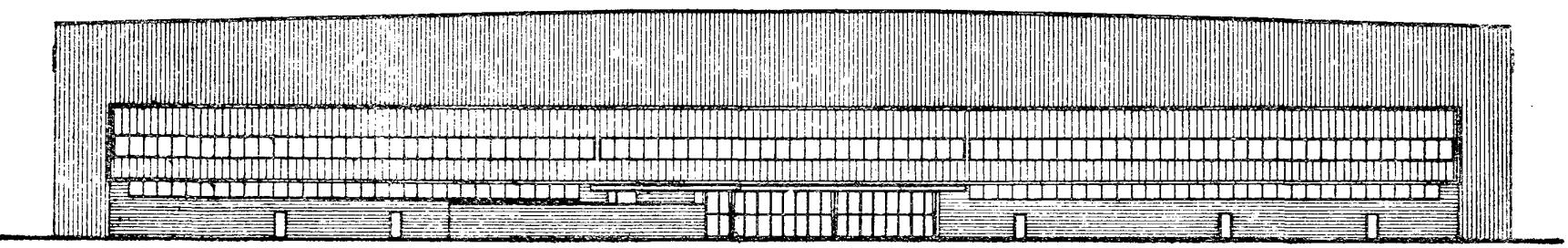

\section{alzado occidental}

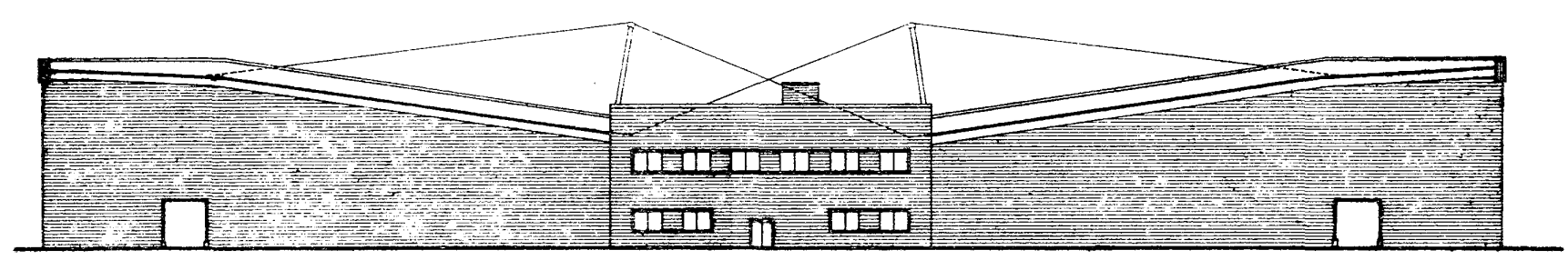

\section{sección transversal}

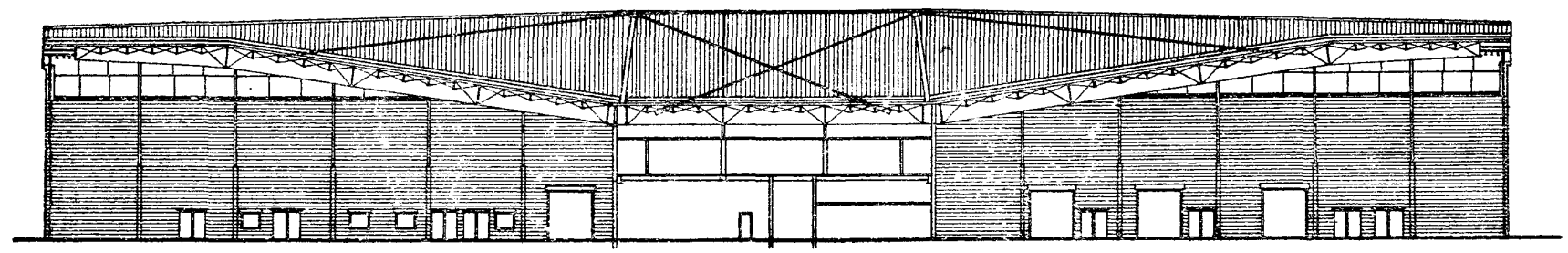

A partir de estos soportes o columnas se ha formado la planta superior, que tiene una doble función: Primero, actuar como arriostramiento entre columnas, tanto en esta primera planta como en la segunda; segundo, aportar el peso muerto para los anclajes de los cables de las ménsulas. Como arriostramiento contra la acción del viento y posibles deformaciones, también se arriostró siguiendo las direcciones de las diagonales.

Terminado el cuerpo central, el objetivo inmediato fué el montaje de las vigas-cajón que forman las dos ménsulas. Estas vigas tienen $48 \mathrm{~m}$ de longitud y se han formado empalmando las de $22 \mathrm{~m}$ con las que arrancan del cuerpo central. Estos dos trozos se soldaron en el suelo y se montaron formando una sola pieza. Para el montaje de estas vigas se utilizó una torre que ascendía por medio de gatos.

Finalmente, se montaron los montantes que sirven de soporte a los cables de suspensión y, seguidamente, estos mismos cables. Sobre estos montantes, de $8 \mathrm{~m}$ de altura, se dispusieron unas sillas de apoyo de los cuatro cables que sostienen cada viga, anclando después las dos extremidades. Las torres de gatos sostenían las ménsulas un poco más elevadas de la cota definitiva, lo que permitió un buen ajuste y fácil maniobra de cables.

Los proyectistas tuvieron especial interés en conservar la misma tensión en cada uno de los cuatro cables que soportan la misma viga, condición que era preferente a que los distintos juegos de cables trabajasen con igual carga en las distintas vigas. 

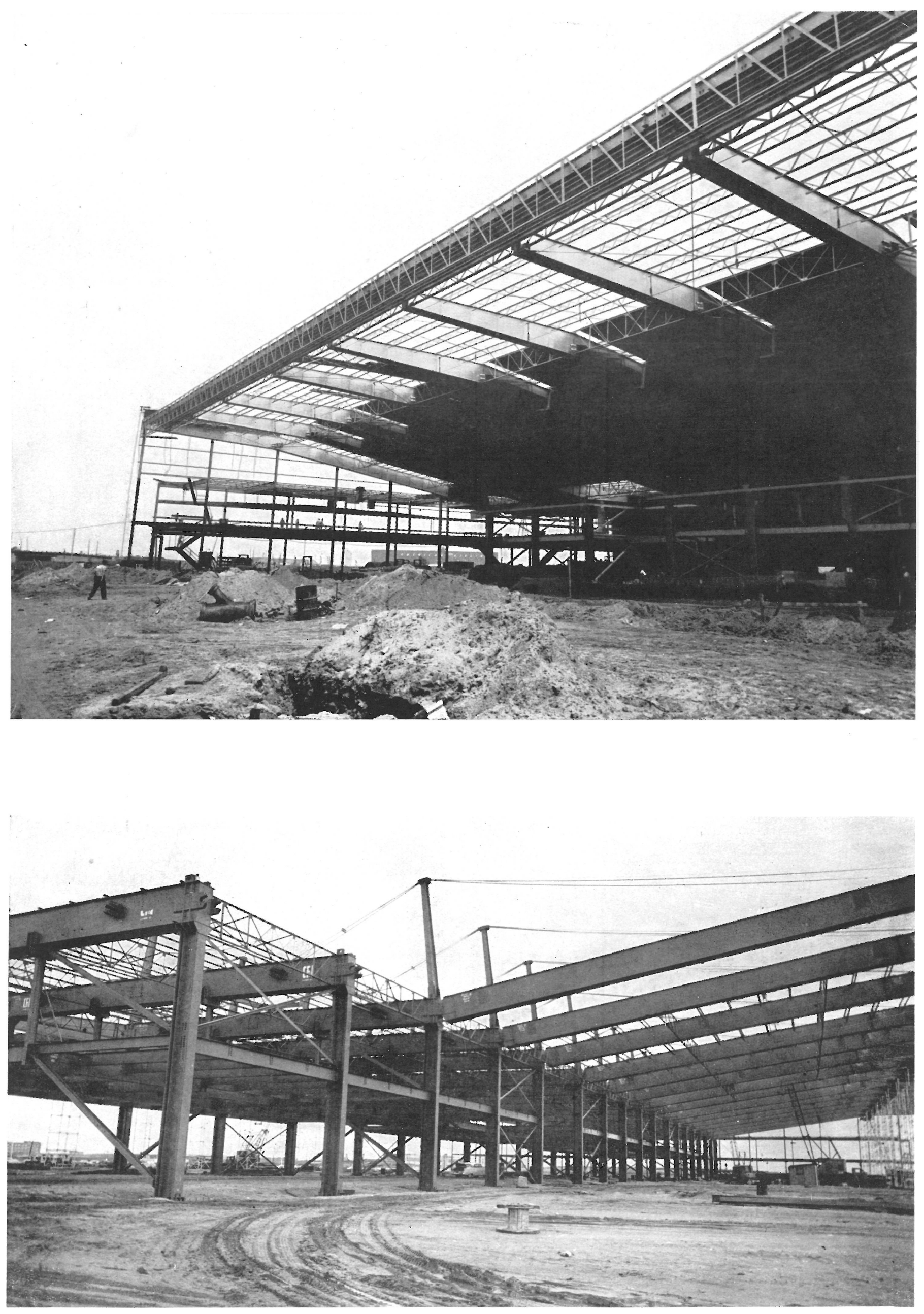


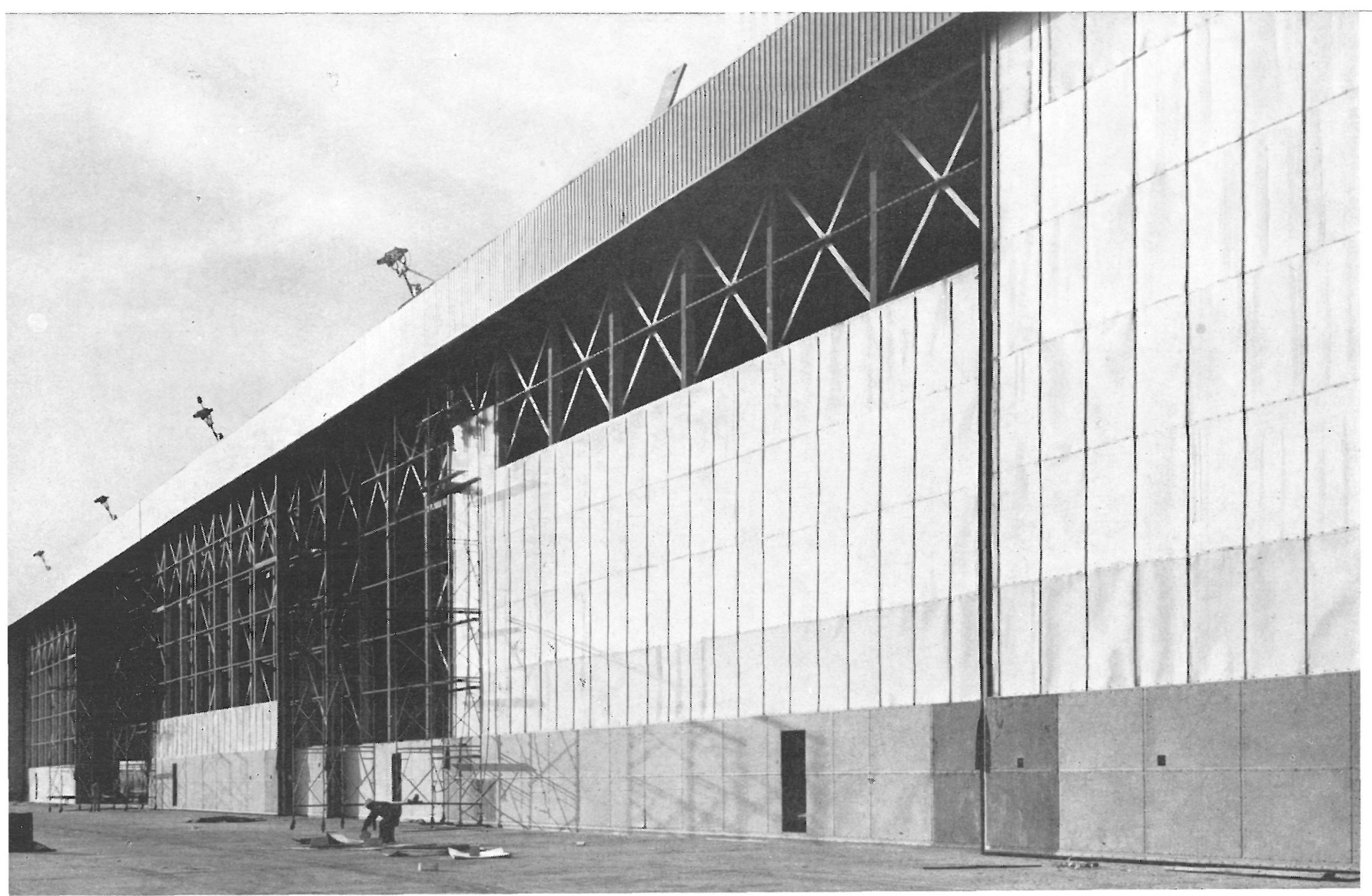

Cada una de las piezas que constituyen los anclajes de los cables que suspenden la viga iba prevista con un gancho de amarre para un cable suplementario auxiliar, que se utilizó para poner en tensión los definitivos. Este cable auxiliar se amarró a un remolque, de 75 toneladas de peso, que tiraba de él hasta que un dinamómetro intercalado indicaba la tensión de su anclaje. En este momento, una grúa, situada entre el remolque y el hangar, tiraba verticalmente, a 90 grados, del cable, con objeto de lograr la tensión final de anclaje. Cuando se llegó a esta última tensión, se acuñó el cable y chapas de sujeción para constituir el anclaje final.

Una vez colocadas las correas y los elementos de rigidez, se procedió a la colocación de los elementos de cerramiento. Cierran el hangar seis puertas, de $26 \mathrm{~m}$ de luz cada una, que ruedan sobre tres vías, sobre cuyos carriles carga el peso, mientras que en la parte superior se han previsto unas guías de apoyo, pero no de carga alguna.

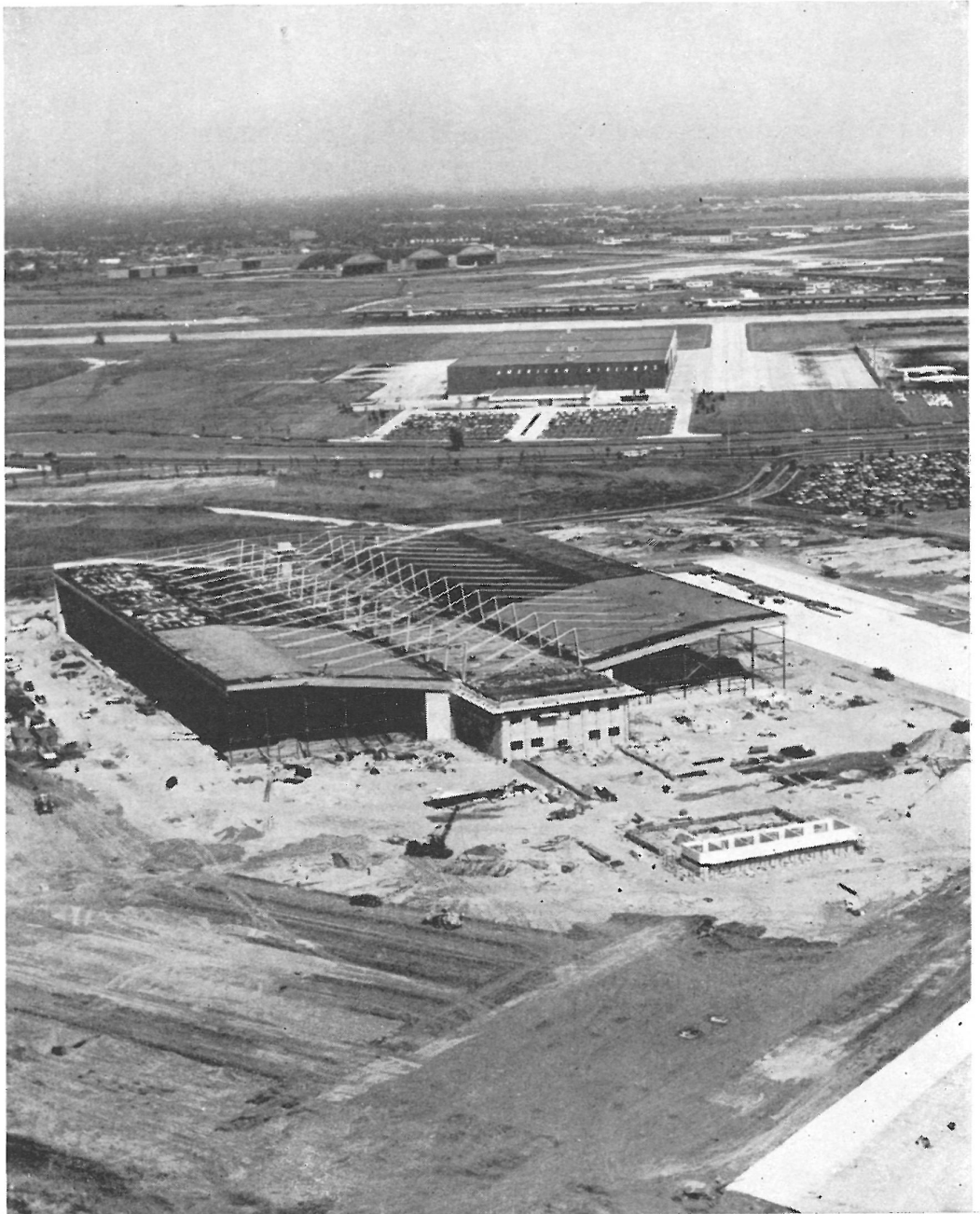

